\title{
PENGARUH PENDIDIKAN KESEHATAN TERHADAP KEMAMPUAN KELUARGA DALAM MERAWAT KLIEN RESIKO PRILAKU KEKERASAN
}

\author{
${ }^{1}$ Diana Arianti, ${ }^{2}$ Yesi Idra Gusmiati \\ ${ }^{1}$ S-1 Keperawatan STIKes Alifah Padang \\ dianaarianti@stikesalifah.ac.id \\ ${ }^{2}$ S-1 Keperawatan STIKes Alifah Padang \\ yesiidragusmiati87@gmail.com
}

\begin{abstract}
ABSTRAK
World Health Organization (WHO) padatahun 2010 memperkirakanmasalahgangguanjiwatidakkurangdari 450 jutapenderitayangditemukan di dunia. KhususnyaIndonesia mencapai 2,5juta60\% yang terdiridaripasienresikoprilakukekerasan. Tujuan penelitian ini untuk mengetahui pengaruh pendidikan kesehatan terhadap kemampuan keluarga dalam merawat klien resiko prilaku kekerasan di unit pelayanan jiwa RSJ. Prof dr. HB. Sa'Anin Padang. Jenis penelitian Kuantitatif “Quasy Eksperiman”dengan desain "OneGrup Pretest-Postest. Populasi penelitian ialah keluarga yang merawat klien Resiko Perilaku Kekerasan sebanyak 71 orang dengan jumlah sampel 15 orang menggunakan teknik accidental sampling.Penelitian dilaksanakan pada Bulan Desember 2015 - Agustus 2016. Hasil penelitian dari 15 responden didapatkan rata-rata kemampuan keluarga merawat klien resiko prilaku kekerasan sebelum diberikan pendidikan kesehatan 10,07 dan Sesudah diberikan pendidikan kesehatan didapatkan Rata-rata kemampuan keluarga merawat klien resiko prilaku kekerasan 12,07. Ada pengaruhkemampuan keluarga dalam merawat klien gangguan jiwa dengan masalah resiko perilaku kekerasan sebelum dan sesudah di berikan pendidikan kesehatan.Pendidikan kesehatan mempengaruhi kemampuan keluarga dalam merawat klien. Diharapkan keluarga dapat menerapkan bagaimana cara latihan fisik dngan cara tarik nafas dalam, verbal dengan mengungkapkan perasaan, meminta, menolak dengan baik, spiritual dan sesuai dengan kegiatan harian.
\end{abstract}

Kata Kunci:Pendidikan kesehatan,keluarga, perilaku kekerasan

\begin{abstract}
World Health Organization (WHO) in 2010 estimated that the problem of mental disorder is not less than 450 million cases detected in the world. Particularly Indonesia reaches 2.5 million $60 \%$ consisting of patients risk of violent behavior Risk Behaviour The purpose of this study to determine the effect on the ability of Family Health Education in Maintain Client Risk Behaviours Violence in Mental Services Unit A (UPJ.A) R.S.J Prof Dr. HB. Sa'anin Padang 2016. Quantitative research type "quasy Experiments" with desaign "One Group Pretest-Posttest. The study population is families who care for clients Risk Behavior Violence many as 71 people with a sample of 15 people using accidental sampling technique. The experiment was conducted in December 2015 - August 2016. The data is processed by using a computerized test of T test dependent.The results of the 15 respondents obtained an average family's ability treating clients before the risk of violent behavior are given health education After 10.07 and are given health education obtained average family's ability treating clients risk violent behavior 12.07. There is the influence the family's ability to care for clients with mental disorders with the risk of violent behavior problems before and after given health education. Health education affect the family's ability to care for the client. Expected families can apply how physical exercise dngan way take a deep breath, verbally express theirfeelings, ask, refuse properly, in accordance with the spiritual and daily activities.
\end{abstract}

Keywords: Health education, family, 


\section{PENDAHULUAN}

Menurut Undang-undang kesehatan jiwa No.18 tahun 2014 kesehatan jiwa adalah kondisi dimana seseorang individu dapat berkembang secara fisik, mental, spiritual, dan social sehingga individu tersebut menyadari kemampuan sendiri, dapat mengatasi tekanan, dapat bekerja secara produktif, dan mampu memberikan kontribusi untuk komunitasnya.

Data yang dikeluarkan oleh Departemen Kesehatan da nWorld Health Organization (WHO) pada tahun 2010 memperkirakan masalah gangguan jiwa tidak kurang dari 450 juta penderita yang ditemukan di dunia. Khususnya Indonesia mencapai 2,5 juta $60 \%$ yang terdiri dari pasien resiko prilaku kekerasan (Wirnata, 2012).

Berdasarkan Riset Kesehatan Dasar (2013) Prevelensi gangguan jiwa berat secara Nasional mencapai $1,7 \%$. Di urutan pertama gangguan jiwa tertinggi di DIY 2,7 juta, Aceh 2,7 juta, Sulawesi Selatan 2,6 juta, Bali 2,3 juta, Jawa Tengah 2,3 juta, Jawa Timur 2,2 juta, Bangka Belitung 2,2 juta, NTB 2,1 juta, dan Sumbar 1,9 juta. Jumlah penduduk yang mengalami gangguan jiwa berat di Sumatera Barat semakin banyak. Penderita gangguan jiwa berat di Sumatera Barat merupakan peringkat kesembilan yaitu sebanyak 1,9 juta. Di Sumaetra Barat gangguan jiwa dengan perilaku kekerasan juga mengalami peningkatan dari 2,8 meningkat menjadi 3,9\%.

Perilaku kekerasan didalam gangguan jiwa merupakan salah satu respons marah yang diekspresikan oleh seseorang dengan melakukan ancaman, mencederai orang lain, dan merusak lingkungan sekitar(Keliat, 2011).Tanda dan gejala secara fisik ialah tampak muka merah, pandangan mata tajam, mengatupkan rahang dengan kuat, mengempalkan tangan, jalan mondar mandir, secara verbal klien berbicara kasar, suara tinggi dan berteriak, dan mengancam secara fisik yang menunjukkan perilaku kekerasan(Videbeck, 2008).Perilaku kekerasan suatu akibat yang ekstrim dari marah, ketakutan, atau panik. Keadaan yang timbul karena tingginya tingkat emosi seseorang. Perasaan frustasi, benci, atau marah dan penggunaan koping yang kurang efektif (Kusmawati, 2011).

Perawat memberikan upaya kesehatan jiwa kepada individu, keluarga dan komunitas agar mampu melakukan perawatan pada diri sendiri, anggota keluarga dan anggota masyarakat lain.Peran serta keluarga sangat penting untuk menyembuhkan pasien karena keluarga merupakan sistem pendukung yang terdekat bagi
pasien.Keluarga agar selalu dilibatkan dalam perencanaan, perawatan dan pengobatan, persiapan pemulangan pasien, dan rencana perawatan tindak lanjut dirumah. Hal ini akan memotivasi keluarga agar berpartisipasi aktif dalam upaya membantu memecahkan masalah pasien (Suliswati, 2005).

Tugas keluarga menurut Friedman (2010) dalam bidang kesehatan yaitu, mengenal masalah kesehatan setiap anggota keluarga, mengambil keputusan untuk melakukan tindakan yang tepat bagi keluarga, memberi keperawatan kepada aggota keluarga yang sakit atau yang tidak dapat membantu dirinya sendiri karena cacat atau usianya terlalu muda, mempertahankan suasana dirumah yang menguntungkan bagi kesehatan dan perkembangan kepribadian anggota keluarga, mempertahankan hubungan timbal balik antara keluarga dan lembaga kesehatan, pemanfaatan fasilitas kesehatan.

Pendidikan kesehatan adalah upaya dalam pembelajaran kepada masyarakat agar melakukan tindakan-tindakan (praktek) untuk mengatasi masalah di masyarakat, kegiatan ini dapat meningkatkan kesehatannya. Perubahan atau tindakan pemeliharaan dan peningkatan kesehatan yang di hasilkan oleh pendidikan kesehatan ini didasarkan kepada pengetahuan dan kesadarannya melalui proses pembelajaran. Sehingga prilaku tersebut di harapkan akan berlangsung lama dan menetap (Notoatmodjo, 2010).

Tujuan penelitian untuk mengetahui pengaruh pendidikan kesehatan terhadap kemampuan keluarga dalam merawat klien resiko prilaku kekerasan di RSJ. Prof dr. HB Saanin Padang”.

\section{METODE}

Berdasarkan latar belakang yang ada, maka ruang lingkup penelitian ini adalah ada pengaruh pendidikan kesehatan terhadap kemampuan keluarga dalam merawat klien resiko prilaku kekerasan di UPJ.A Prof. HB.Sa' anin Padang tahun 2016. Populasi keluarga yang merawat klien dengan resiko perilaku kekerasan sebanyak 71 orang dengan sampel 15 orang keluarga. Penelitian dilakukan di Unit Pelayanan Jiwa A RSJ Prof. HB. Sa'anin Padang. Penelitian dilaksanakan pada Bulan Desember 2015 - Agustus 2016. Pengumpulan data pada tanggal 18 Juli - 01 Agustus 2016. Penelitian ini merupakan penelitian kuantitatif dengan desain penelitian Quasi Experiment dengan jenis rancanganone gruppretest-postest. Sampling yang dipakai dalam penelitian ini adalah teknik 
"accidental sampling" dan jumlah sampel yang digunakan pada penelitian ini adalah 15 orang. Pengolahan data menggunakan uji statistik T test.

\section{HASIL}

\section{Kemampuan Keluarga Sebelum diberikan Pendidikan Kesehatan}

\section{Tabel 1}

\begin{tabular}{cccc}
\hline Mean & $\begin{array}{c}\text { Standar } \\
\text { Deviasi }\end{array}$ & Min & Max \\
\hline 10,07 & 1,387 & 8 & 13 \\
\hline
\end{tabular}

Berdasarkan tabel 1 dapat dilihat bahwa ratarata kemampuan keluarga dalam merawat klien resiko perilaku kekerasan sebelum di lakukan pendidikan kesehatan dengan nilai mean 10,07, standar deviasi 1,387 dan nilai terendah adalah 8 dan nilai tertinggi adalah 13 .

\section{Kemampuan Keluarga Sesudah diberikan Pendidikan Kesehatan}

Tabel 2

\begin{tabular}{cccc}
\hline Mean & $\begin{array}{c}\text { Standar } \\
\text { Deviasi }\end{array}$ & Min & Max \\
\hline 12,07 & 1,534 & 9 & 14 \\
\hline
\end{tabular}

Berdasarkan tabel 2 dapat dilihat bahwa ratarata kemampuan keluarga dalam merawat klien resiko perilaku kekerasan sesudah di lakukan pendidikan kesehatan dengan nilai mean 12,07, standar deviasi 1,534 dan nilai terendah adalah 9 dan nilai tertinggi adalah 14 .

\section{Pengaruh Pendidikan Kesehatan Terhadap Kemampuan Keluarga dalam Merawat Klien Gangguan Jiwa dengan Masalah Resiko Perilaku Kekerasan}

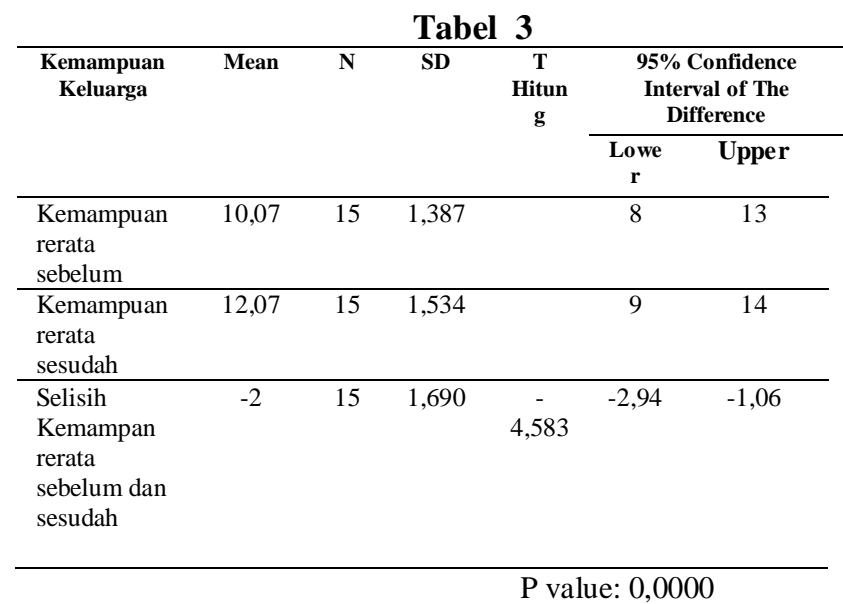

Tabel 3 menunjukkan rata-rata kemampuan keluarga sebelum dan sesudah diberikan pendidikan kesehatan dengan perbedaan -2,00.
Setelah dilakukan uji statistik T-test didapatkan nilai $\mathrm{p}$ value $(0,000)$. Maka terdapat perbedaan kemampuan keluarga dalam merawat klien gangguan jiwa dengan masalah resiko perilaku kekerasan.

\section{PEMBAHASAN}

\section{Kemampuan Keluarga Sebelum Diberikan Pendidikan Kesehatan Tentang Resiko Perilaku Kekerasan}

Hasil penelitian menunjukkan bahwa kemampuan keluarga dalam merawat klien resiko perilaku kekerasan sebelum dilakukan tindakan pendidikan kesehatan dengan nilai mean 10,07, median 10 standar deviasi 1,387 dan nilai terendah adalah 8 dan nilai tertinggi adalah 13. Hal ini dapat dilihat dari pengisian kuesioner kognitif dimana $40 \%$ keluarga belum mengetahui berbicara kotor tanda dan gejala dari resiko perilaku kekerasan dan pada kuesioner psikomotor $40 \%$ keluarga belum mampu mengajarkan latihan melakukan tarik nafas dalam ketika pasien emosi, mengajarkan cara meminta dan menolak dengan baik, mengajak pasien melakukan kegiatan agama lainnya misalnya mengaji dan wirid.

Penelitian ini hampir sama dengan hasil penelitian yang dilakukan oleh Nina (2015) mengenai Pengaruh Pendidikan Kesehatan tentang resiko prilaku kekerasan (RPK) Terhadap Pengetahuan Keluarga Dalam Merawat Pasien Di Poli Jiwa RSJD DR. RM. Soedjarwadi Klaten Jawa Tengan didapatkan hasil pre test 12 responden memiliki pengetahuan yang baik dan postest menunjukkan bahwa 20 responden memiliki pengetahuan yang baik menunjukkan perbedaan rata-rata sebelum dan sesudah responden diberikan oleh pendidikan kesehatan tentang resiko perilaku kekerasan

Pendidikan kesehatan adalah suatu penerapan konsep pendidikan dalam bidang kesehatan.Dilihat dari segi pendidikan, pendidikan kesehatan adalah suatu pedagogik praktis atau praktik pendidikan.Oleh sebab itu, konsep pendidikan kesehatan adalah konsep pendidikan yang diaplikasikan pada bidang kesehatan. Pendidikan adalah suatu proses belajar yang berarti dalam pendidikan itu terjadi proses pertumbuhan, perkembangan, atau perubahan ke arah yang lebih dewasa, lebih baik, dan lebih matang pada diri individu, kelompok atau masyarakat (Notoatmodjo, 2011).

Perilakukekerasandianggapsebagaisuatuakibat yang ekstrimdarimarah, ketakutan, 


\begin{abstract}
ataupanik.Suatukeadaan yang
timbulkarenatingginyatingkatemosiseseorang.Pera

saanketikaseseorangmerasafrustasi, benci, ataumarahdanterkadangpenggunaankoping yang kurangefektif. Hal inidapatmempengaruhiperilakuseseorang, dikarenakankeadaanemosi yang secaramendalamdanberlebihantersebutterkadangpe rilakumenjadiagresif atau melukai karena penggunaan koping yang kurang bagus (Kusmawati, 2010).

Menurut peneliti rendahnya kemampaun keluarga dalam merawat pasien gangguan jiwa ini dikarenakan masih ada keluarga yang memiliki pendidikan rendah SD dan SMP sebanyak $20 \%$. Pendidikan yang rendah pada keluarga ini menyebabkan keluarga tidak dapat mengaplikasikan informasi yang diberikan oleh petugas kesehatan tentang perawatan perilaku kekerasan. Selain pendidikan, umur juga mempengaruhi kemampuan keluarga dalam merawat klien perilaku kekerasan. Dimana pada penelitian ini keluarga lebih banyak pada rentang usia masa dewasa. Pada masa ini keluarga belum banyak pengalaman dalam hal merawat klien perilaku kekerasan.
\end{abstract}

\section{Keluarga Pengetahuan Sesudah diberikan Pendidikan Kesehatan}

Hasil penelitian menunjukkan bahwa rata-rata kemampuan keluarga dalam merawat klien resiko perilaku kekerasan sesudah di lakukan pendidikan kesehatan dengan nilai mean 12,07, median 12 standar deviasi 1,534 dan nilai terendah adalah 9 dan nilai tertinggi adalah 14. Hasil perkembangan setelah diberikan pendidikan kesehatan dimana dari pengisian kuesioner kognitif meningkat 86,6\% keluarga belum mengetahui berbicara kotor tanda dan gejala dari resiko perilaku kekerasan dan pada kuesioner psikomotor $73,3 \%$ keluarga belum mampu mengajarkan latihan melakukan tarik nafas dalam ketika pasien emosi, mengajarkan cara meminta $(80 \%)$ dan menolak dengan baik $(53,3 \%)$, mengajak pasien melakukan kegiatan agama lainnya misalnya mengaji dan wirid.

Penelitian ini hampir sama dengan hasil penelitian yang dilakukan oleh Nina (2015) mengenai Pengaruh Pendidikan Kesehatan tentang resiko prilaku kekerasan (RPK) Terhadap Pengetahuan Keluarga Dalam Merawat Pasien Di Poli Jiwa RSJD DR. RM. Soedjarwadi Klaten Jawa Tengan didapatkan hasil pre test 12 responden memiliki pengetahuan yang baik dan postest menunjukkan bahwa 20 responden memiliki pengetahuan yang baik menunjukkan perbedaan rata-rata sebelum dan sesudah responden diberikan oleh pendidikan kesehatan tentang resiko perilaku kekerasan.

Pendidikan kesehatan adalah suatu proses yang menjembatani kesenjangan antara informasi dan tingkah laku kesehatan. Pendidikan kesehatan memotifasi seseorang untuk menerima informasi kesehatan dan berbuat sesuai dengan informasi tersebut agar mereka menjadi lebih tahu dan lebih sehat. Sasaran pendidikan kesehatan adalah masyarakat atau individu baik yang sehat maupun sakit. Sasaran pendidikan kesehatan tergantung pada tingkat, dan tujuan penyuluhan yang diberikan. Lingkungan pendidikan kesehatan di masyarakat dapat dilakukan melalui berbagai lembaga dan organisasi masyarakat (Notoatmodjo, 2012).

Menurut peneliti meningkatnya kemampuan keluarga dalam merawat klien gangguan jiwa resiko perilaku kekerasan ini dikarenakan sudah mendapatkan pendidikan kesehatan tentang cara merawat yang baik bagi pasien resiko perilaku kekerasan selama 2 minggu dengan 3 kali perlakuan. Dimana perkembangan setelah diberikan pendidikan kesehatan dimana dalam pengisian kuesioner kognitif meningkat $86,6 \%$ keluarga sudah mengetahui jika klien berbeicara kotor adalah tanda dan gejala dari resiko perilaku kekerasan dan pada kuesioner psikomotor 73,3\% keluarga sudah mampu mengajarkan latihan melakukan tarik nafas dalam ketika pasien emosi, keluarga sudah mampu mengajarkan cara meminta dan menolak dengan baik, 53,3\% mengajak pasien melakukan kegiatan agama lainnya misalnya mengaji dan wirid.

\section{Pengaruh Pendidikan Kesehatan Terhadap Kemampuan Keluarga dalam Merawat Klien Gangguan Jiwa dengan Masalah Resiko Perilaku Kekerasan}

Hasil penelitian menunjukkan rata-rata kemampuan keluarga sebelum dan sesudah diberikan pendidikan kesehatan dengan perbedaan 2,00. Setelah dilakukan uji statistik T-test didapatkan nilai $\mathrm{p}$ value $(0,000)$. Maka terdapat perbedaan kemampuan keluarga dalam merawat klien gangguan jiwa dengan masalah resiko perilaku kekerasan. 
Penelitian ini hampir sama dengan hasil penelitian yang dilakukan oleh Nina (2015) mengenai Pengaruh Pendidikan Kesehatan tentang resiko prilaku kekerasan (RPK) Terhadap Pengetahuan Keluarga Dalam Merawat Pasien Di Poli Jiwa RSJD DR. RM. Soedjarwadi Klaten Jawa Tengan didapatkan hasil pre test 12 responden memiliki pengetahuan yang baik dan postest menunjukkan bahwa 20 responden memiliki pengetahuan yang baik menunjukkan perbedaan rata-rata sebelum dan sesudah responden diberikan oleh pendidikan kesehatan tentang resiko perilaku kekerasan.

Selain itu penelitian ini hampir sama dengan penelitian yang dilakukan Sudirman (2014) pengaruh pendidikan kesehatan terhadap peningkatan pengetahuan keluarga tentang perawatan pasien dengan masalah gangguan halusinasi pendengaran di RSKD provinsi Sumatera Selatan ditemukan hasil pengetahuan keluarga sebelum dan sesudah diberikan tindakan mengalami pningkatan $p$ value $=0,011$.

Pendidikan kesehatan jiwa pada keluarga adalah memberikan bimbingan dan penyuluhan kesehatan jiwa dalam rangka meningkatkan kesehatan jiwa keluarga, mencegah penyakit, dan mengenali gejala gangguan jiwa secara dini dan upaya pengobatannya.Pendidikan kesehatan ini bertujuan untuk mencapai derajat kesehatan yang optimal bagi seluruh keluarga. Untuk mencapai tujuan tersebut diharapkan keluarga dapat memberikan stimulasi dalam perkembangan anak, menumbuhkan hubungan interpersonal, mengerti tentang kesehatan jiwa dan gangguan kesehatan jiwa, mengetahui penyebab gangguan jiwa, ciri-ciri gangguan jiwa, fungsi dan tugas keluarga, upaya pencegahan gangguan jiwa oleh keluarga, upaya perawatan pasien gangguan jiwa di rumah sakit umum dan puskesmas (Suliswati, 2005).

Menurut analisa peneliti memberikan pendidikan kesehatan dapat meningkatkan kemampuan keluarga klien karena pendidikan kesehatan ini merupakan upaya untuk menciptakanperilaku masyarakat untuk memperoleh kesehatan. Setelah dilakukan pendidikan kesehatan selama 3 hari perlakuan selama \pm 20 menit perhari pada masing-masing keluarga ditemukan perbedaan sebelum dan sesudah diberikan perlakuan. Namun pada penelitian ini ditemukan 4 orang keluarga tidak mengalami perubahan kemampuan. Hal ini dikarenakan 2 orang memiliki pekerjaan sebagai membuat perabotan dan bengkel mobil di rumah pedagang sehingga mereka tidak konsentrasi dalam mengamati peneliti pada waktu memberikan pendidikan kesehatan dan 2 orang ibu rumah tangga. Pada kedua ibu rumah tangga ini juga tidak konsentrasi dalam mengamati peneliti pada waktu memberikan pendidikan kesehatan karena mereka memiliki anak yang banyak dan masih kecil.

\section{KESIMPULAN}

Berdasarkan hasil penelitian dan pembahasan dapat disimpulkan beberapa hal mengenai Pengaruh pendidikan kesehatan terhadap kemampuan keluarga merawat klien resiko prilaku kekerasan di unit pelayanan jiwa A RSJ. HB. Sa'Anin Padang Tahun 2016, sebagai berikut :Rata-rata nilai mean 10,07, median 10 standar deviasi 1,387 dan nilai terendah adalah 8 dan nilai tertinggi adalah 13. Rata-rata nilai mean 12,07, median 12 standar deviasi 1,534 dan nilai terendah adalah 5 dan nilai tertinggi adalah 9.Ada pengaruh kemampuan keluarga dalam merawat klien gangguan jiwa dengan masalah resiko perilaku kekerasan.

\section{DAFTAR PUSTAKA}

Friedman, M. 2010. Buku Ajar Keperawatan keluarga : Riset, Teori, dan Praktek. Edisi ke-5. Jakarta: EGC

Keliat, B.A,. 2011. Proses keperawatan kesehatan jiwa. Jakarta :EGC

Kemeskes RI, 2012. Gangguan Jiwa. Jakarta

Kusumawati F dan Hartono Y. 2011. Buku Ajar Keperawatan Jiwa. Jakarta : EGC

Profil RSJ.HB. Saanin Padang. 2015

Notoadmodjo, S. (2010). Metodologi Penelitian Kesehatan. Edisi revisi. Jakarta : PT Rhineka Cipta.

Suliswati et al. (2005). Konsep Dasar Keperawatan Kesehatan Jiwa. Jakarta : EGC.

Videbeck, Sheila L,. (2008). Buku Ajar Keperawatan Jiwa. Jakarta: EGC

WHO. (2010). Data Penderita Kanker Serviks. Http;//www.google.com. Diakses 20 Mei 2012. 